\title{
Método não destrutivo pelo processo de cravação de tubos na instalação de novas redes
}

\author{
Christofi Issa Estephan', Bernardo Santos Alves', Marcelo Tsuyoshi Haraguchi', \\ Fernando Ernesto Ucker', Pedro Daniel da Cunha Kemerich² \\ ' Laboratório de Planejamento e Monitoramento Ambiental - LPMA/UFSM, Curso de Engenharia Ambiental da Universidade Federal de \\ Santa Maria/CESNORS, Frederico Westphalen, Brasil. \\ ${ }^{2}$ Coordenador do Curso de Engenharia Ambiental da Universidade Federal de Santa Maria/CESNORS, Frederico Westphalen, Brasil.
}

\section{Resumo}

O estudo de caso será aplicado, através do método não destrutivo, na execução da rede coletora de esgoto do condomínio Terras Alphaville, na BR-060, em Anápolis-GO. Tal método pode ser utilizado para a concepção de redes públicas de esgoto sanitário, água, gás, telecomunicações ou outra tubulação que, devido às condições do local, torne o método tradicional inviável. A travessia sob a BR-060 será executada por método não destrutivo, pelo processo de cravação de tubo, através de macacos hidráulicos, sem a retirada de solo, mantendo o maciço do solo inalterado, sem prejuízos significativos para o trânsito da rodovia em questão, em função da importância econômica e logística da rodovia e da região.

Palavras-chave: Método não destrutivo, cravação de tubo, rede coletora de esgoto, BR-060

\begin{abstract}
The case study will be applied by non-destructive method in the implementation of sewage disposal system Alphaville condominium Lands on US-060 in Anapolis-GO. This method can be used for the design of public sanitary sewer, water, gas, telecommunications or other pipe due to site conditions the traditional method becomes impracticable. The crossing under the BR-060 is performed by non-destructive method, the process of crimping the tube by hydraulic jacks without removal of soil, while keeping unchanged the mass of soil without significant damage to the transit of highway in question as a function of economic importance and logistics of highway and the area.
\end{abstract}

Keywords: Non-destructive method, piling pipe, sewage disposal system, BR-060 


\section{INTRODUÇÃO}

A construção de infraestruturas por Métodos não Destrutivos (MND) está presente em nossas vidas, para isso basta lembrar que um túnel rodoviário é uma construção por MND, pois evitou a destruição de áreas de conservação, permitindo a transposição de obstáculos, naturais ou não. Com o advento de instalações e reabilitações de redes (água, esgotos, gás, comunicação etc.) na época mais recente (ultimas duas ou três décadas), esses serviços encontraram um ambiente no subsolo, totalmente ocupado por instalações dos mais diversos serviços, como mencionado anteriormente.

O Brasil é um país que está em um momento de pleno crescimento econômico, constata-se que a infraestrutura não acompanha tal desenvolvimento. Principalmente quando se analisa que as tubulações da maioria dos centros das grandes cidades de nosso país estão subdimensionadas. A grande maioria das obras de recuperação ou, até mesmo, de implantação de novas redes (ex: água, esgoto, telefonia e internet ou até mesmo transporte de pessoas) se torna inviável por estar em trânsito de pessoas e serviços. Portanto, o método tradicional, com abertura de valas e remoção de solo, torna-se um método inviável e um problema para os centros urbanos.

Segundo Abratt (2007), os métodos não destrutivos podem reduzir os danos ambientais e os custos sociais e, ao mesmo tempo, representam uma alternativa econômica para os métodos de instalação, reforma e reparo com vala a céu aberto. Vêm sendo vistos, cada vez mais, como uma atividade de aplicação geral e não como uma especialidade. Muitas empresas de instalação de redes têm uma tendência a aplicar os Métodos Não Destrutivos (MND) sempre que possível, em função dos custos e dos aspectos ambientais e sociais.

Para Novulari (2003), este é um método utilizado para assentamento de tubulação no solo por meio de abertura de valas. Essas valas são abertas desde a superfície até o ponto em que a tubulação é instalada, como em obras convencionais que, cotidianamente, utilizam máquinas para abertura das valas.

Por isso, o objetivo deste trabalho foi avaliar o método não destrutivo em uma obra de engenharia, no município de Anápolis, Estado de Goiás. Além disso, objetivou-se, também, analisar o método e suas inúmeras possibilidades de execução.

\section{METODOLOGIA}

Este estudo foi realizado a partir do projeto elaborado pela empresa Kawana Sub-empreiteira, em uma obra no condomínio Terras Alphaville, da construtora ADM Engenharia (Figura 1). Este projeto conta com as cotas iniciais e finais da rede coletora de esgoto e, também, com todas as informações adicionais para execução do furo pelo MND, tais como inclinação, distância, tipo de solo e demais informações.

O poço de ataque possuía $6,50 \mathrm{~m}$ de comprimento e 2,50 m de largura. Já o poço de recepção tinha 3,00 de comprimento e 2,50 m de largura (este é o espaço mínimo necessário para a operação da máquina), e a profundidade dos poços será de acordo com o projeto,

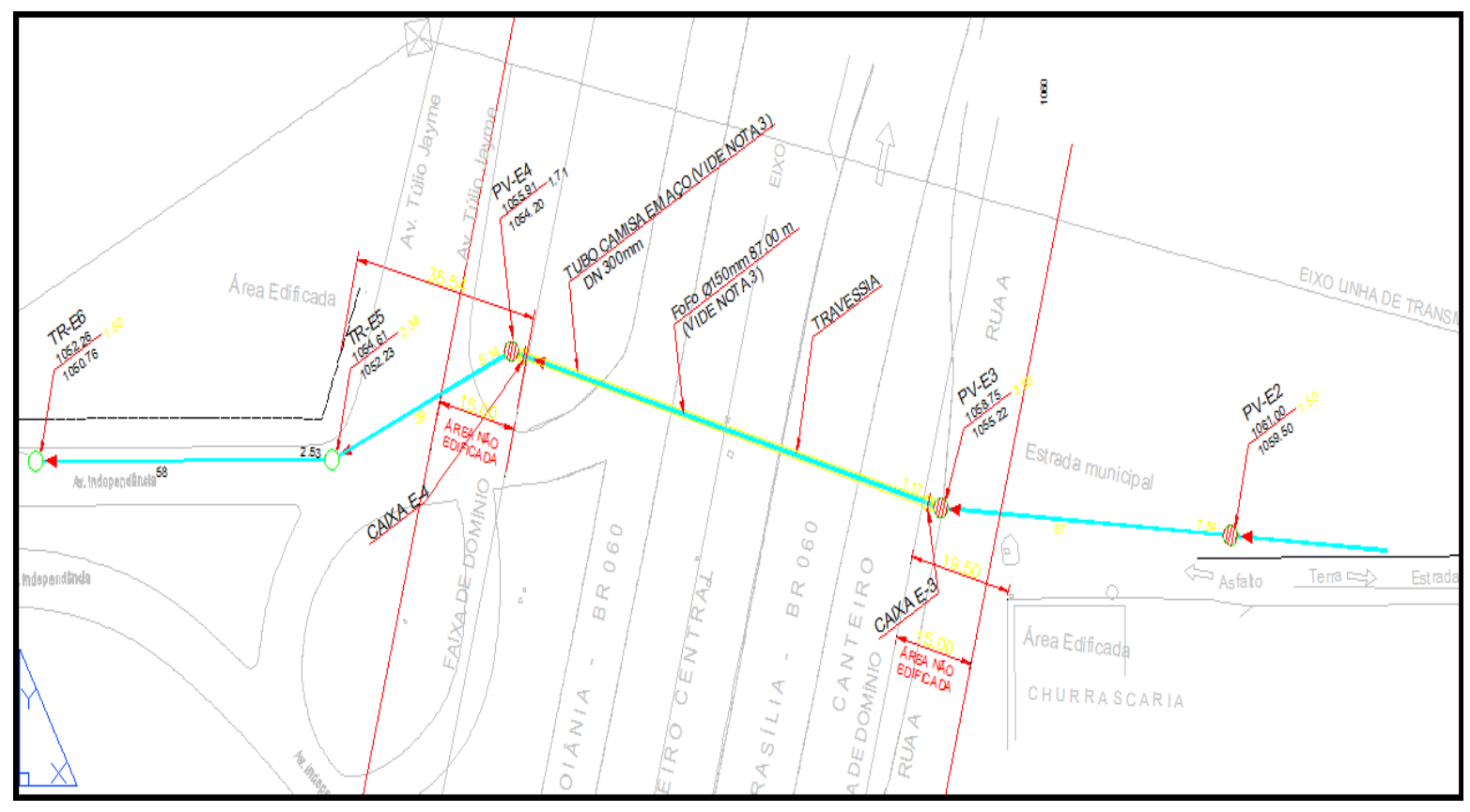

Figura 1. Localização do empreendimento estudado. 


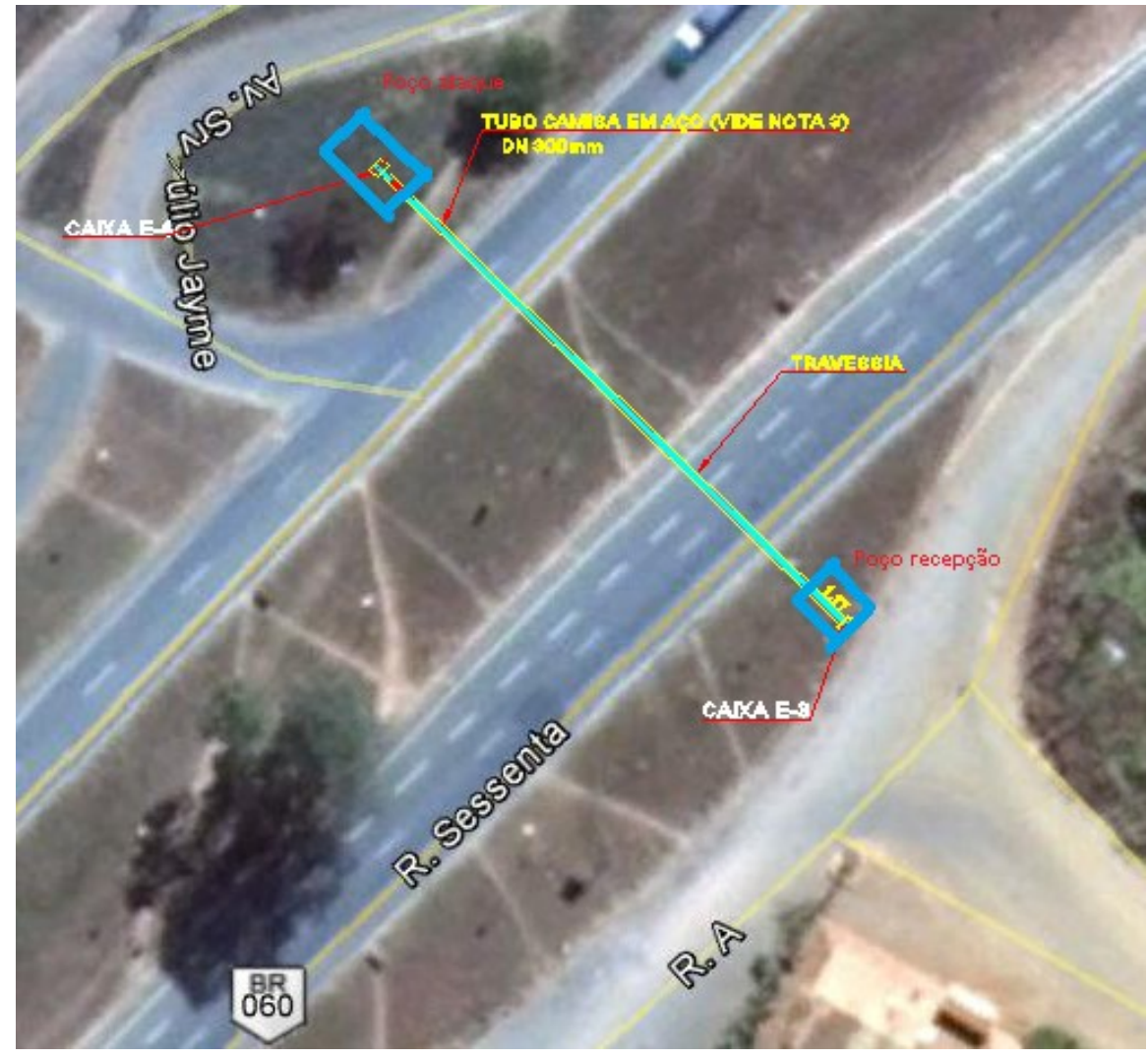

Figura 2. Projeção futura da rede e dos poços para execução da obra

podendo variar, segundo dados topográficos.

Os poços estavam localizados na mesma posição das caixas E3 e E4, conforme projeto. Os poços serão fechados com tapume, contendo placas reflexivas sinalizadoras. Os tapumes serão instalados a 1,00 das bordas dos poços (Figura 2). O escoramento do posto de serviço será executado em pranchas de madeira.

Além de ser um ítem crítico e muito questionado atualmente, a segurança, neste caso, também é diretamente ligada a quem transita pela BR - 060, por este motivo e dentro das especificações de projeto aprovadas no DNIT (Departamento Nacional de Transito), as proximidades das obras receberão sinalização, alertando os condutores de veículos que estão sendo executadas obras na região e que tais obras contêm vala aberta, o que propicia o risco de algum acidente.

\section{RESULTADOS E DISCUSSÕES}

O valor cobrado pela empresa ADM ENGENHARIA foi de R $\$ 124.000,00$ pela execução da obra, em preço global. Todavia, mesmo com alguns contratempos na execução da obra, superou os gastos, que foram de $\mathrm{R} \$ 101.000,00$, incluindo todos os descontos e pagamentos de mão de obra e equipamentos. Obtevese, assim, um lucro de $\mathrm{R} \$ 23.000,00$, para a empresa contratada, pelo condomínio Terras Alphaville, para execução desta obra de travessia. Lucro este que representa, aproximadamente, 19\% do valor da obra. Logo, muito satisfatório, devido ao curto período que esta obra levou.

O lucro poderia ter sido muito maior caso a empresa possuísse as máquinas e a mão de obra qualificada para tal serviço, mas, como este serviço estava incluso num contrato de serviços com o condomínio Terras Alphaville, a empresa preferiu sub-empreitar o serviço para uma empresa especializada, enquanto ela fazia toda a rede de esgoto no interior do condomínio.

O método utilizado, mesmo sendo o mais adequado para este tipo de obras, ainda encontra alguns problemas que estão sempre sujeitos a acontecer. No caso da obra em estudo, o primeiro problema surgiu antes mesmo de a obra ter iniciado, pois o órgão regulador das rodovias federais, o DNIT, esteve em greve durante muito tempo, não podendo autorizar o início da mesma.

Por mais que o método convencional, também chamado de abertura de valas, seja mais barato, a obra de esgoto do condomínio Terras Alphaville seria imprópria, 
não possuindo a melhor maneira de ser executada por tal método destrutivo, devido à sua localização ser na BR 153, os transtornos seriam grandes por parar uma rodovia federal com grande tráfego de automóveis e caminhões, sendo esta caminho para a capital do país e pra ao porto seco, localizado em Anápolis.

O próprio órgão regulador destes tipos de obras em rodovias, o DNIT, não aceita intervenções destrutivas em suas rodovias que possuam tráfego contínuo, pois a abertura de valas necessitaria a interrupção do tráfego da rodovia. Existe, ainda, um grande risco de acidentes e de recalque no asfalto no novo, que seria reposto, às pressas, para que retomasse o tráfego normal.

A cidade de Anápolis se encontra em um momento em que o trânsito pode ser considerado caótico, isso porque há a construção do novo viaduto nesta mesma BR em que a travessia pelo método não destrutivo foi feita. A cidade inteira e a rodovia na altura do DAIA (Distrito Agro Industrial de Anápolis) estão muito congestionadas, impossibilitando rotas alternativas para que pudéssemos executar esta obra por um método destrutivo, apenas visando o preço da obra.

\section{CONCLUSÕES}

Conclui-se, ao final deste estudo de caso, que o método é totalmente satisfatório, embora mais trabalhoso, tendo a necessidade de tubo camisa (que é de um preço muito mais elevado do que os tubos comumente usados) e, também, de maquinários específicos (que também tem preço muito elevado perante o método comum). Elevando o preço da obra, quase, três vezes o preço de uma obra igual, executada pelo método tradicional, por abertura de valas.

O método atende a especificações únicas do DNIT, que apenas sendo feito desta maneira tal obra seria viabilizada. Possui, também, vantagens relevantes para a execução da mesma, pois tem necessidade de uma equipe reduzida, com relação ao método tradicional, e mesmo com os problemas que tivemos em nosso caso, os dias trabalhados não excederam os dias trabalhados caso fosse possível fazer pelo método tradicional.

Manteve, também, o pavimento intacto em uma região de grande trafego de caminhões. Caso fosse feito um corte no pavimento, por mais bem feito que seja sua reposição, sempre teríamos um ponto de patologias crônicas no local, o que causaria transtornos à população e aos usuários da rodovia.

Para as empresas que executam tais obras, a vantagem é o alto preço cobrado para execução, obtendo, assim, uma margem de lucro satisfatória para as contratadas para este serviço, mesmo ocorrendo imprevistos em alguns casos. Como foi o caso da empresa ADM Engenharia, neste caso do condomínio Terras Alpha- ville, em Anápolis-GO.

\section{REFERÊNCIAS}

ABNT - ASSOCIAÇÃO BRASILEIRA DE NORMAS TÉCNICAS. NBR 12266: Projeto e execução de valas para assentamento de tubulação de água esgoto ou drenagem urbana. Rio de Janeiro, 1992.

ABNT - ASSOCIAÇÃO BRASILEIRA DE NORMAS TÉCNICAS. NBR 9648: Estudo de concepção de sistemas de esgoto sanitário. Rio de Janeiro, 1986.

ABRATT - ASSOCIAÇÃO BRASILEIRA DE TECNOLOGIA NÃO DESTRUTIVA. Disponível em: <http://www.abratt.org.br/>. Acesso em: 25 de abr. de 2013.

AQUACON, (2008), III Congresso Brasileiro de MND I No-Dig Edição Latino-Americana, Disponível em: <http://www.acquacon.com.br/nodigbrasil2008/port/sobre.html>Acesso em: 2013

COUTINO, P.T. \& NEGRO JUNIOR, A. (1995). Túneis não tripulados. São Paulo, 1995

FORTES. D, (2010) Estudo do uso do método não destrutivo em travessias de tubulações sob interferência. Disponível em <http://civil.uefs.br/DOCUMENTOS/DIEGO\%20REBOU\%C3\%87AS\%20 FORTES.pdf $>$. Acesso em 2013.

KAWANA, (2013), Método de cravação de tubos Detalhamento. Goiânia, 2013

MOUTINHO, A.C \& ARIARATNAM, S.T, Introdução ao Método Não Destrutivo. Disponível em: $<$ http://www.abratt.org.br/seminario/intro.pdf>. Acesso em: 2013

NUVOLARI, A. (2003). Esgoto sanitário: coleta transporte, tratamento e reuso agrícola - São Paulo: Editora Blucler, 2003.

PALAZZO, S. (2007) Introdução ao Método Não destrutivo. Disponível em:<http://site.sabesp.com. br/uploads/file/audiencias_inova\%C3\%A7\%C3\%A3o/Introdu\%C3\%A7\%C3\%A3o\%20aos\%20 m\%C3\%A9todos\%20n\%C3\%A3o\%20-\%20destrutivos.pdf>. Acesso em 2013.

PND, Métodos não destrutivos. Disponível em: $<$ http://www.pnd-sp.com.br/secao_metodosnaodestrutivos.shtml> Acesso em: 2013 
REN, (2007). Ficha de prevenção e segurança abertura de valas ou trincheiras Disponível em: <http:// pt.scribd.com/doc/41584959/FPS-18-Abertura-deValas-ou-Trincheiras-Ed02>. Acesso em: 2013.

SANEAGO.O esgoto em Goiânia. [S.1.], 2004. Disponível em: <http://www.saneago.com.br/novasan/ index.php?id=esgoto6\&tit=esgoto $>$. Acesso em: 2013

SABESP, Métodos Não Destrutivos em Obras de Saneamento. Disponível em $<$ http://site.sabesp. com.br/site/interna/Default.aspx?secaoId=365> . Acesso em: 2013

SUZUKI, C. Y. \& ROCHA, M. N. [et, all], (2010) Aplicação do método não destrutivo do tipo pipe bursting para substituição de recalque de esgoto sanitário - Estudo de caso da estação da estação elevatória de esgoto Riviera. Disponível em <http:// engenharia.anhembi.br/tcc-10/civil-05.pdf> (2010). Acesso em: 2013. 